\title{
Malignant melanoma and pregnancy
}

\author{
Delia Cudalba', Nicolae Gica ${ }^{1,2}$, Radu Botezatu1,2, Corina Gica ${ }^{2}$, Anca Marina Ciobanu ${ }^{1,2}$, \\ Brindusa Ana Cimpoca ${ }^{1}$, Gheorghe Peltecu ${ }^{1,2}$, Anca Maria Panaitescu ${ }^{1,2}$ \\ ${ }^{1}$ Filantropia Clinical Hospital, Bucharest, Romania \\ 2"Carol Davila" University of Medicine and Pharmacy, Bucharest, Romania
}

\begin{abstract}
Malignant melanoma is one of the most frequent cancers diagnosed during pregnancy. Any pigmented skin lesions that change the color should be examined by an experienced dermatologist and if suspected, should be biopsied. Recent studies showed that malignant melanoma in pregnancy has not a worse outcome compared with non-pregnant state.

Diagnosis of melanoma does not require an early delivery excepted pregnant patients with poor prognosis that need more aggressive treatment. Diagnosis and treatment need to be established in specialized centers with a multidisciplinary team. Pregnancy monitoring should be performed by team consisting of an obstetrician, a neonatologist and a specialist in fetal medicine.
\end{abstract}

Keywords: melanoma, malignancy, pregnancy, diagnosis, treatment

\section{INTRODUCTION}

Cancer during pregnancy, although an uncommon but challenging event, has been steadily increasing along with the trend towards delayed childbearing. Over the last 40 years the incidence has risen from 1:2000 in 1964 to 1:1000 deliveries in $2000[1,2,3]$.

Cancer represents the second most common cause of death for women of childbearing age [4]. The most common cancers occurring in pregnancy are melanoma, breast cancer, cervical cancer, and hematopoietic malignancies [2]. Melanoma, lung cancer, lymphomas and leukemias are known to be the only histological types that metastasize to the placenta and fetus, in third of all cases being reported melanomas [5].

Pregnancy is a state of various immune and hormonal changes that can determine a number of benign skin conditions or can awake preexisting skin conditions or pregnancy-specific dermatoses. Distinguishing benign skin disorders from life threatening conditions is therefore of great importance [6].

It has been reported that about $35 \%$ of women diagnosed with melanoma are of childbearing age and melanoma would be the most common malignancy in women of reproductive age [2,7]. It is estimated that melanoma is the most common cancer diagnosed during pregnancy, accounting for $31 \%$ of all malignancies. Even in those instances, only $0.9 \%$ of those women will have their melanoma diagnosed during pregnancy $[8,9]$.

Melanoma diagnosed during pregnancy or up to one year after delivery is defined as pregnancy-associated melanoma (PAM). Whether PAM has distinct etiopathological or clinical implications, management and prognosis is still debated in the literature. The aim of this work is to provide an overview of the available evidence on this topic.

\section{METHODS}

A systematic literature electronic search for reviews and guidelines was undertaken using Pub Med and the official websites of Dermatology, Oncology and Obstetrics and Gynecology associations. Search words were "melanoma", "pregnancy", "pregnancy-associated melanoma", "therapy". Publications were selected based on accessibility to full paper article, quality evaluation, publication 
year. The publications used are mentioned in References section.

\section{THE INFLUENCE OF PREGNANCY ON MELANOMA DEVELOPMENT}

There are various hypotheses on how the physiology of pregnancy may have an impact on melanoma development.

During pregnancy the increase in the level of circulating hormones, the intravascular volume expansion and the compression from the enlarging uterus determine cutaneous physiological changes. There is an increase in melanogenesis, angiogenesis, keratinocyte proliferation and collagen synthesis [10].

Pigmentary changes are the most frequent skin modification in pregnancy. Estrogens and progesterone stimulate melanogenesis. There is also the contribution of the increased secretion of melanocyte-stimulating hormone. Hyperpigmentation occurs on the areolae, axillae, thighs, anogenital and periumbilical areas, and linea nigra but can affect also naevi, freckles and recent scars [10].

Pregnant women commonly experiencing skin pigmentation may lead to misdiagnosis or late diagnosis. Regarding the changes in naevi that occur during pregnancy, studies report lack of evidence, therefore guidelines recommend to investigate any suspicious pigmented lesion [11].

During pregnancy there are several changes in the woman's immune system. There are various biological factors, as placental growth factor, human chorionic gonadotropin, estrogen, progesterone that are involved in some of the pregnancy processes as inducing immune tolerance toward the fetus, neoangiogenesis and tissue invasion necessary for placentation [12]. There is a transition from a $\mathrm{T}$ helper 1 lymphocyte profile to a $\mathrm{T}$ helper 2 profile, regulating differently the levels of cytokines produced, increasing the risk of autoimmune disease and cell mediated immunity, therefore increasing the susceptibility to skin disease $[13,14]$.

There are several studies on indolamine 2,3 dioxygenase (IDO) - an enzime expressed in the placenta, involved in the process of immune tolerance. It was acknowledged that patients where IDO was positive in the lymph nodes draining a melanoma had poorer outcome than patients with IDO negative lymph nodes [14].

Estrogen and progesterone are known to determine an increase in melanin production [15]. Although estrogen is reported to have an impact on the development of other cancers, the effect on melanoma is not well understood and continues to be debated. Recent studies stated that reduced estrogen receptor $\mathrm{B}(\mathrm{ERb})$ expression would be linked to increased Breslow thickness of melanomas. Therefore, ERb expression could be accounted as a prognostic indicator 16].

As lymphangiogenesis increases during pregnancy, PAM has a greater potential to metastasize. This points out the significance of sentinel node biopsy where indicated [17].

Pregnancy-associated plasma protein A (PAPP-A) is a glycoprotein produced by the placenta and decidua and has been widely used in prenatal genetic screening. It was reported that PAPP-A would be linked to melanoma progression, cases of metastatic melanoma having higher levels of PAPP-A. It was demonstrated that lowering PAPP-A would interfere with melanoma cell migration [18].

There is also a theory on the impact of growth factors active in pregnancy on melanoma. Several studies concluded that PAM had a more increased Breslow thickness than other melanomas followed in women of similar age. Therefore, there is an assumption that growth factors expressed in pregnancy would magnify tumorigenesis $[19,20]$.

\section{THE IMPLICATIONS OF MELANOMA IN PREGNANCY}

Melanoma is one of the few histological types of cancer that metastasize to the fetus and placenta. It is documented that melanoma represents $30 \%$ of placental metastases. Regardless of that, pregnancies with melanoma metastases are an infrequent occurrence and don't alter the well-being of the new born. However, affected fetuses have poor outcomes [21,22].

An interesting remark regarding infants born to patients diagnosed with melanoma was related to fetal growth. Studies reported increased rates of large for gestational age infants. It was assumed that these phenomena would be linked to growth factors that could both influence the fetal growth and the tumor growth. IGF-2 mRNA-binding protein 3 (IMP-3) is a protein involved in embryogenesis, expressed in fetal tissues, absent in adult tissues. It was detected in various cancers, including melanoma and levels of IMP-3 were higher in metastatic melanoma than in early stages melanoma, so it was concluded that IMP-3 secreting melanomas would increase the risk of large for gestational age fetuses $[7,23,24]$. 
Regarding timing of delivery, early delivery would be recommended to allow an aggressive treatment for patients with poor prognosis. Otherwise, delivery at term should be tried to achieve $[25,26]$. In less favorable situations, when advanced disease is diagnosed in the first or second trimester, termination of pregnancy would allow using more therapeutic possibilities. Even this would facilitate the clinical management of the case, the medical decision is emotionally and ethically difficult and it depends on the woman's will and decision, anteriorly well counseled [19].

\section{MANAGEMENT}

Investigations during pregnancy may have some limitations, as the fetus must be protected from potentially harmful exposures but the main diagnostic tools are still available for using. Dermoscopy is a non-invasive diagnostic method that can be performed safely during pregnancy. It improves the diagnostic accuracy and allows melanoma recognition at early stages. Biopsies performed under local anesthesia are also safe during pregnancy $[27,28]$.

After diagnosis, a management plan for both the mother and the fetus should be established by a multidisciplinary team. The caregivers have to take into account how the pregnant status modifies the standard treatment plan and the patient's prognosis.

Primary melanoma management is not different for pregnant women. Biopsies and wide local excision are considered safe.

One of the key prognostic indicators for patients with clinically localized melanoma is the status of the sentinel node. Sentinel lymph node biopsy has only prognostic significance and is not performed with curative intent [29]. If sentinel node biopsy is required, lymphoscintigraphy using Technetium 99 may be used. The use of patent blue dye is not recommended due to possible teratogenicity and the risk of anaphylaxis [25].

If the clinical situation requires general anesthesia for surgical procedures it is recommended to adjourn the intervention until the second trimester, because of the slightly higher risk of miscarriage in the first trimester.

The management of systemic disease takes into account the site and number of metastases and the stage of pregnancy. If the targeted tumor is not located near the uterus, for example in brain metastases, radiotherapy may be used. Otherwise, it should be postponed until postpartum.
Immunotherapy or target therapy with BRAF and MEK inhibitors are commonly used as standard therapy plan for melanoma but are not recommended during pregnancy and lactation.

\section{RISKS, PROGNOSIS, SURVIVAL RATES}

Predominantly celtic origin populations and high levels of solar UV exposure made Australia and New Zealand the countries with the highest incidence of melanoma in the world. In 2018 the International Agency for Research on Cancer estimated for Australia an incidence rate of 33.6 per 100,000 [30]. Therefore, evidence-based, accurate guidelines for managing melanoma are constantly updating. Regarding pregnancy-associated melanoma their clinical practice guidelines report that pregnancy does not increase the risk of developing melanoma or subsequent melanoma. Moreover, the prognosis for melanoma in pregnant women is no different from the one diagnosed in non-pregnant women of similar age. Concerning the risk of recurrence it is recommended to defer pregnancy for two to five years after being diagnosed with high-risk melanoma. Recurrence depends on the thickness of the melanoma - if the ones smaller than $0.5 \mathrm{~mm}$ have $1-3 \%$ risk of recurrence within 5 years, those greater than $4 \mathrm{~mm}$ have $50 \%$ risk of recurrence within 2 years [11].

Europe has an incidence rate of melanoma of $10-25$ per 100,000 , Norway, Denmark and Netherlands reporting the highest rates [9]. European guidelines recommendations are consistent with the Australian ones. Considering the evidence gathered so far, pregnancy is not reported to affect melanoma risk or survival and childbearing after a melanoma diagnosis with a favorable outcome is considered possible after 2 years as long as individual factors are taken into consideration.

There is controversy in the literature as to whether pregnancy-associated melanoma has worse survival than other melanomas. A Swedish cohort study concluded also that the mortality in PAM is similar with the one in non-pregnant women of childbearing age [31]. In contrast, there are various studies with opposite conclusions. A cohort study from Norway proved higher mortality rates for melanoma associated with pregnancy [8]. A study reviewing 11 reports found like-wise greater rates for PAM - 56\% increased risk of mortality compared to melanoma in women who were not pregnant [32]. There were also found $17 \%$ higher mortality and 50\% higher recurrence rate for PAM in a meta-analysis of 15 studies [33]. 


\section{CONCLUSIONS}

As pregnancy-associated melanoma is increasing in frequency, this article aims to raise awareness of this malignancy in this particular context. Most of the diagnostic approaches can be performed safely and should not be delayed. Any lesion that meets the diagnostic criteria for melano-

Conflict of interest: none declared

Financial support: none declared

\section{REFERENCES}

1. Williams TJ, Turnbull KE. Carcinoma in situ and pregnancy. Obstet Gynecol. 1964 Dec;24:857-64.

2. Pavlidis NA. Coexistence of pregnancy and malignancy. Oncologist. 2002;7(4):279-87.

3. Smith LH, Danielsen B, Allen ME, Cress R. Cancer associated with obstetric delivery: results of linkage with the California cancer registry. Am J Obstet Gynecol. 2003 Oct;189(4):1128-35.

4. Siegel RL, Miller KD, Jemal A. Cancer statistics, 2019. CA Cancer J Clin. 2019 Jan;69(1):7-34.

5. Alexander A, Samlowski WE, Grossman D, Bruggers CS, Harris RM, Zone JJ, Noyes RD, Bowen GM, Leachman SA. Metastatic melanoma in pregnancy: risk of transplacental metastases in the infant. J Clin Oncol. 2003 Jun 1;21(11):2179-86.

6. Sävervall C, Sand FL, Thomsen SF. Dermatological Diseases Associated with Pregnancy: Pemphigoid Gestationis, Polymorphic Eruption of Pregnancy, Intrahepatic Cholestasis of Pregnancy, and Atopic Eruption of Pregnancy. Dermatol Res Pract. 2015; 2015:979635.

7. Lee YY, Roberts CL, Dobbins T, Stavrou E, Black K, Morris J, Young $\mathrm{J}$. Incidence and outcomes of pregnancy-associated cancer in Australia, 1994-2008: a population-based linkage study. BJOG. 2012 Dec;119(13):1572-82.

8. Stensheim H, Møller B, van Dijk T, Fosså SD. Cause-specific survival for women diagnosed with cancer during pregnancy or lactation: a registry-based cohort study. J Clin Oncol. 2009 Jan 1;27(1):45-51.

9. Garbe C, Amaral T, Peris K, Hauschild A, Arenberger P, Bastholt L, et al.; European Dermatology Forum (EDF), the European Association of Dermato-Oncology (EADO), and the European Organization for Research and Treatment of Cancer (EORTC). European consensusbased interdisciplinary guideline for melanoma. Part 1: Diagnostics - Update 2019. Eur J Cancer. 2020 Feb;126:141-158.

10. Soutou B, Aractingi S. Skin disease in pregnancy. Best Pract Res Clin Obstet Gynaecol. 2015 Jul;29(5):732-40.

11. Clinical Practice Guidelines for the Management of Melanoma in Australia and New Zealand. Available at: https://www.health.govt.nz/ system/files/documents/publications/melanoma-guideline-nov08-v2.pdf.

12. Enninga EA, Holtan SG, Creedon DJ, Dronca RS, Nevala WK, Ognjanovic S, Markovic SN. Immunomodulatory effects of sex hormones: requirements for pregnancy and relevance in melanoma. Mayo Clin Proc. 2014 Apr;89(4):520-35.

13. Vaughan Jones S, Ambros-Rudolph C, Nelson-Piercy C. Skin disease in pregnancy. BMJ. 2014 Jun 3;348:g3489.

14. Still R, Brennecke S. Melanoma in pregnancy. Obstetric Medicine 2017;10(3):107-112.

15. Dürr S, Kindler V. Implication of indolamine 2,3 dioxygenase in the tolerance toward fetuses, tumors, and allografts. J Leukoc Biol. 2013 May;93(5):681-7.

16. Vora RV, Gupta R, Mehta MJ, Chaudhari AH, Pilani AP, Patel N. Pregnancy and skin. J Family Med Prim Care. 2014 Oct-Dec; 3(4):318-24.

17. de Giorgi V, Gori A, Grazzini M, Rossari S, Scarfi F, Corciova S, Verdelli A, Lotti T, Massi D. Estrogens, estrogen receptors and melanoma. Expert Rev Anticancer Ther. 2011 May;11(5):739-47.

18. Khosrotehrani K, Nguyen Huu S, Prignon A, Avril MF, et al. Pregnancy promotes melanoma metastasis through enhanced lymphangiogenesis. Am J Pathol. 2011 Apr;178(4):1870-80. ma should be biopsied. While primary disease has an accessible management, metastatic disease should benefit from multidisciplinary approach. Counselling and continuous support are an essential part of the management.

\section{Acknowledgement}

All authors equally contributed to this article.

19. Prithviraj P, Anaka M, McKeown SJ, Permezel M, et al. Pregnancy associated plasma protein-A links pregnancy and melanoma progression by promoting cellular migration and invasion. Oncotarget. 2015 Jun 30;6(18):15953-65.

20. Daryanani D, Plukker JT, De Hullu JA, Kuiper H, Nap RE, Hoekstra HJ. Pregnancy and early-stage melanoma. Cancer. 2003 May 1;97(9):2248-53.

21. MacKie RM, Bufalino R, Morabito A, Sutherland C, Cascinelli N. Lack of effect of pregnancy on outcome of melanoma. For The World Health Organisation Melanoma Programme. Lancet. $1991 \mathrm{Mar}$ 16;337(8742):653-5

22. Sebire NJ, Jauniaux E. Fetal and placental malignancies: prenatal diagnosis and management. Ultrasound Obstet Gynecol. 2009 Feb;33(2):235-44.

23. Broer N, Buonocore S, Goldberg C, Truini C, Faries MB, Narayan D, Ariyan S. A proposal for the timing of management of patients with melanoma presenting during pregnancy. J Surg Oncol. 2012 Jul 1;106(1):36-40.

24. Bannister-Tyrrell M, Roberts CL, Hasovits C, Nippita T, Ford JB. Incidence and outcomes of pregnancy-associated melanoma in New South Wales 1994-2008. Aust N Z J Obstet Gynaecol. 2015 Apr;55(2):116-22.

25. Sheen YS, Liao YH, Lin MH, Chu CY, et al. IMP-3 promotes migration and invasion of melanoma cells by modulating the expression of HMGA2 and predicts poor prognosis in melanoma. $J$ Invest Dermatol. 2015 Apr;135(4):1065-1073.

26. Peccatori FA, Azim HA Jr, Orecchia R, Hoekstra HJ, Pavlidis N, Kesic V, Pentheroudakis G; ESMO Guidelines Working Group. Cancer, pregnancy and fertility: ESMO Clinical Practice Guidelines for diagnosis, treatment and follow-up. Ann Oncol. 2013 Oct;24 Suppl 6:vi160-70.

27. Grunewald S, Jank A. New systemic agents in dermatology with respect to fertility, pregnancy, and lactation. J Dtsch Dermatol Ges. 2015 Apr;13(4):277-90.

28. Giuffrida R, Conforti C, Di Meo N, Deinlein T, Guida S, Zalaudek I. Use of noninvasive imaging in the management of skin cancer. Curr Opin Oncol. 2020 Mar;32(2):98-105.

29. Balch CM, Soong SJ, Gershenwald JE, Thompson JF, Reintgen DS, et al. Prognostic factors analysis of 17,600 melanoma patients: validation of the American Joint Committee on Cancer melanoma staging system. J Clin Oncol. 2001 Aug 15;19(16):3622-34.

30. Gershenwald JE, Thompson W, Mansfield PF, Lee JE, Colome MI, Tseng CH, Lee JJ, Balch CM, Reintgen DS, Ross MI. Multiinstitutional melanoma lymphatic mapping experience: the prognostic value of sentinel lymph node status in 612 stage I or II melanoma patients. J Clin Oncol. 1999 Mar;17(3):976-83.

31. Global Cancer Observatory: Cancer Today. International Agency for Research on Cancer; 2018. Available at: https://gco.iarc.fr/tomorrow/ en/about.

32. Johansson AL, Andersson TM, Plym A, Ullenhag GJ, Møller H, Lambe M. Mortality in women with pregnancy-associated malignant melanoma. J Am Acad Dermatol. 2014 Dec;71(6):1093-101.

33. Byrom L, Olsen C, Knight L, Khosrotehrani K, Green AC. Increased mortality for pregnancy-associated melanoma: systematic review and meta-analysis. J Eur Acad Dermatol Venereol. 2015 Aug; 29(8):1457-66. 